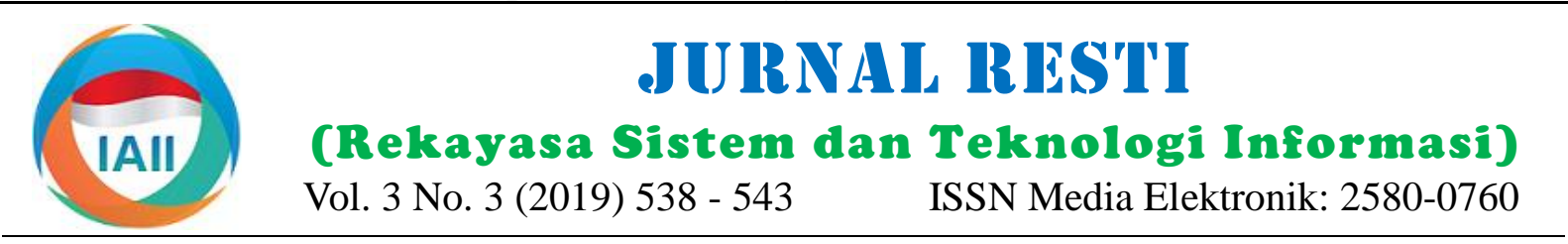

\title{
Validitas dan Praktikalitas E-Modul Pelatihan Mikrotik Guru Teknik Komputer Jaringan
}

\author{
Khairul Anshari ${ }^{1}$, Kasman Rukun ${ }^{2}$, Asrul Huda ${ }^{3}$ \\ ${ }^{1,2,3}$ Pendidikan Teknologi Kejuruan, Fakultas Teknik, Universitas Negeri Padang \\ 1anshari_khairul@yahoo.co.id, ${ }^{2}$ kasman.rukun@gmail.com, ${ }^{3}$ asrulhuda@gmail.com
}

\begin{abstract}
The achievement of the Teacher Competency Test (UKG) results has not yet reached the expected percentage target. Based on the analysis, teachers need to increase their knowledge and skills about microtics. The module that is commonly used is a pdfformat module that contains power point slides, the module does not have a more detailed description of the proxy use steps. This study aims to develop microtic training modules and reveal their validity and practicality. This type of research is development research using plomp and nieveen models, namely preliminary research, prototyping stage, and assessment phase. The instrument used was a questionnaire of validity and practicality. The results of the module validity test research by three module experts obtained results in the valid category. The validation of the material by three experts, the material was obtained with a valid category. Based on practicality tests by network computer engineering teachers at SMKN 2, SMKN 3, SMKN 5, SMKN 6 and SMKN 8 Padang shows that the module has a very high practicality category. Based on the results of the study, it can be concluded that the microtic training e-module is considered valid by experts as well as practical by instructors and trainees
\end{abstract}

Keywords: E-Module, Mikrotik, Training, Validity, Practicality

\begin{abstract}
Abstrak
Pencapaian hasil Uji Kompetensi Guru (UKG) belum mencapai target persentase yang diharapkan. Berdasarkan analisis guru butuh meningkatkan pengetahuan dan keterampilan tentang mikrotik. Modul yang biasa digunakan adalah modul dengan format pdf yang berisi slide power point, modul tidak memiliki penjelasan yang lebih rinci tentang langkah penggunaan mikrotik. Penelitian ini bertujuan untuk mengembangkan e-modul pelatihan mikrotik dan mengungkapkan validitas dan praktikalitas. Jenis penelitian ini adalah penelitian pengembangan dengan menggunakan model plomp dan nieveen, yaitu preliminary Research, prototyping stage, dan assesment phase. Instrumen yang digunakan adalah kuesioner dalam bentuk lembar angket validitas dan praktikalitas. Hasil penelitian uji validitas modul oleh tiga orang ahli modul diperoleh hasil dengan kategori valid. Pada validasi materi oleh tiga orang ahli materi di peroleh hasil dengan kategori valid. Berdasarkan uji praktikalitas oleh guru teknik komputer jaringan di SMKN 2, SMKN 3, SMKN 5, SMKN 6 dan SMKN 8 Padang menunjukkan bahwa modul memiliki kategori kepraktisan yang sangat tinggi. Berdasarkan hasil penelitian, bisa disimpulkan bahwa e-modul pelatihan mikrotik dinilai valid oleh para ahli serta praktis oleh instruktur dan peserta diklat.
\end{abstract}

Kata kunci: E-Modul, Mikrotik, Pelatihan, Validitas, Praktikalitas

(C) 2019 Jurnal RESTI

\section{Pendahuluan}

Berdasarkan Hasil UKG Nasional 2015, didapatkan rata - rata nasional 50,97 dari target nasional yang ditetapkan pemerintah 55,00. Ini menunjukan masih kurangnya kompetensi guru secara nasional yang perlu ditingkatkan demi tercapainya tujuan pembelajaran nasional.
Berdasarkan hasil observasi pada bidang teknik komputer jaringan (TKJ) terdapat beberapa kebutuhan guru dalam melakukan pelatihan yaitu mengenai mikrotik, cisco, fiber optik, administrasi jaringan, softswitch dan IP V6. Dari hasil yang diperoleh banyak guru yang membutuhkan pelatihan mengenai mikrotik sebanyak 20 orang. Pada rekayasa perangkat lunak

Diterima Redaksi : 11-09-2019 | Selesai Revisi : 06-12-2019| Diterbitkan Online : 14-12-2019 
(RPL) terdapat beberapa kebutuhan guru dalam yang sesuai dengan bidangnya agar lebih efektif dan melakukan pelatihan yaitu mengenai android, web, dan efisien.

java. Dari hasil yang diperoleh banyak guru yang membutuhkan pelatihan tentang android sebanyak 12 orang, dan pada bidang multimedia (MM) terdapat beberapa kebutuhan guru dalam melakukan pelatihan yaitu tentangengenai desain grafis, pembuatan film dan pengambilan gambar, dari hasil yang di peroleh banyak guru yang membutuhkan pelatihan tentang animasi sebanyak 18 orang.

Tabel 1. Hasil Observasi SMK Jurusan Informatika di Sumatera Barat

\begin{tabular}{clrc}
\hline Bidang keahlian & Materi yang dibutuhkan & \multicolumn{2}{c}{ Jumlah } \\
\hline BIDANG TKJ & Mikrotik & 20 & Orang \\
& Cisco & 18 & Orang \\
& Fiber optic & 15 & Orang \\
& Administrasi jaringan & 5 & Orang \\
& Softswitch & 5 & Orang \\
& IP V6 & 4 & Orang \\
BIDANG RPL & Android & 12 & Orang \\
& Web & 10 & Orang \\
BIDANG MM & Java & 7 & Orang \\
& Animasi 2D, 3D & 18 & Orang \\
& Desain Grafis & 10 & Orang \\
& Pembuatan Film & 6 & Orang \\
& Pengambilan Gambar & 2 & Orang \\
\hline
\end{tabular}

Berdasarkan hasil observasi, guru teknik komputer jaringan membutuhkan pelatihan mikrotik, maka peneliti meneliti tentang e-modul mikrotik untuk melaksanakan pelatihan mikrotik. Kekurangan pada emodul mikrotik yaitu tampilan materi seperti powerpoint dengan format pdf, sehingga hanya menampilkan bagian inti materi saja, tanpa penjelasan langkah kerja yang lebih rinci, guru biasanya menggunakan sumber internet untuk dijadikan job sheet, kurangnya materi mengenai troubleshooting pada jaringan mikrotik, menginstal jaringan dan proxy pada mikrotik, dan e-modul masih memuat materi lama yang belum update dengan keadaan sekarang.

Pelatihan merupakan suatu kegiatan untuk memberi pengetahuan dan keterampilan tenaga kerja yang baru ataupun tenaga kerja yang lama. Kemampuan dasar yang diberikan kepada tenaga kerja untuk menambah kemampuan tenaga kerja untuk lebih menguasai bidang kerja yang dimiliki [1]. Pelatihan adalah proses sistematis untuk mengubah perilaku karyawan ke arah yang akan mencapai tujuan organisasi. Training terkait dengan keterampilan dan kemampuan pekerjaan saat ini. Ini memiliki orientasi saat ini dan membantu karyawan menguasai keterampilan dan kemampuan khusus yang diperlukan untuk menjadi sukses [2]. Pelatihan upaya terencana untuk memfasilitasi pembelajaran pengetahuan, keterampilan, dan perilaku yang terkait dengan pekerjaan oleh karyawan [3].

Kesimpulannya bahwa pelatihan adalah suatu upaya untuk meningkatkan kemampuan, keterampilan,

kecakapan serta sikap dan tingkah laku pegawai dalam Mengembangkan e-modul pelatihan mikrotik untuk melaksanakan tanggung jawabnya sebagai tenaga kerja guru informatika bidang teknik komputer jaringan.
Modul merupakan salah satu bentuk bahan ajar yang dikemas secara utuh dan sistematis, didalamnya memuat seperangkat pengelaman belajar yang terencana dan didesain untuk membantu peserta didik menguasai tujuan belajar yang spesifik. Modul minimal memuat tujuan pembelajaran, materi/substansi belajar dan evaluasi [4]. Modul sebagai paket belajar mandiri yang meliputi serangkaian pengalaman belajar yang direncanakan dan dirancang secara sistematis untuk membantu peserta didik mencapai tujuan belajar [5].

Beberapa karakteristik tentang modul diantaranya, self instructrion, self contained, stand alone, adaptive, dan user friendly [4].

E-Modul disebut juga media untuk dipelajari secara mandiri yang berbentuk software atau aplikasi yang dibuka melalui alat elektronik. Mikrotik merupakan sistem operasi dan perangkat lunak yang digunakan untuk menjadi komputer router network yang handal. E-Modul menjadi media sebagai panduan untuk pengembangan bahan ajar yang memiliki keunggulan dalam aspek substansi, desain, penampilan dan penggunaan media pembelajaran [6].

E-modul pelatihan mikrotik yang akan dikembangkan adalah modul yang dibuat berbentuk aplikasi format exe, bisa dijalankan dengan bantuan aplikasi Adobeflash. Proses pembelajaran yang dilakukan mandiri sesuai dengan kemampuan individu masingmasing. E-Modul pelatihan mikrotik yang digunakan diharapkan untuk menjadi sarana atau alat bantu belajar yang efektif dan efisien dalam memanfaatkan waktu serta tenaga menggunakan teknologi komputer dan laptop. E-module adalah pembelajaran dengan menggunakan media komputer, sehingga memungkinkan siswa untuk belajar sesuai dengan kemampuan dan kecepatannya dalam memahami materi pelajaran yang disampaikan[7].

Dengan menggabungkan teks, gambar, audio dan video dalam sebuah e-modul pelatihan mikrotik sehingga diharapkan mampu membuat peserta diklat lebih mudah untuk belajar. Modul pelatihan yang akan dikembangkan adalah modul yang bersifat elektronik atau e-modul yang berbentuk sebuah aplikasi sehingga bisa digunakan di komputer dan laptop peserta diklat. E-modul di rancang menggunakan aplikasi Flipbooks yang diharapkan bisa memudahkan dalam menguasai materi, menarik minat peserta diklat untuk membaca dan memahami materi serta meningkatkan keberhasilan guru dalam meningkatkan kompetensi keahlian. yang diperoleh, maka berikut tujuan penelitian yang dilaksanakan:
Tujuan penelitian disesuaikan dengan rumusan masalah 
Mengembangkan e-modul pelatihan mikrotik yang kelompok kecil (small group evaluation), dan uji coba valid dan praktis untuk guru informatika bidang teknik lapangan (field test) seperti terlihat pada Gambar 1 komputer jaringan.

\section{Metode Penelitian}

Model penelitian yang digunakan adalah Research and development (R\&D). Model pengembangan adalah seperangkat prosedur yang dilakukan secara berurutan dalam melaksanakan perancangan dan pengembangan suatu produk [8]. Metode pengembangan yang digunakan adalah model pengembangan yang dikemukakan [9] yang terdiri dari tiga langkah yaitu preliminary research (Penelitian Pendahuluan), prototyping stage (pengembangan Prototype), dan assesment phase (fase penilaian).

Tabel 2. Kriteria Evaluasi pada Penelitian Pengembangan

\begin{tabular}{|c|c|c|}
\hline Fase & Kriteria & Deskripsi Aktivitas \\
\hline $\begin{array}{l}\text { Penelitian } \\
\text { Pendahuluan }\end{array}$ & $\begin{array}{l}\text { Penekanan pada } \\
\text { validitas isi }\end{array}$ & $\begin{array}{l}\text { Analisis masalah dan } \\
\text { studi literatur. Hasil } \\
\text { dari fase ini adalah } \\
\text { bentuk rancangan awal } \\
\text { prototype }\end{array}$ \\
\hline Tahap & Fokus pada & Pengembangan \\
\hline Pengembangan & $\begin{array}{l}\text { konsistensi } \\
\text { (validitas } \\
\text { konstruk) dan } \\
\text { praktikalitas.. }\end{array}$ & $\begin{array}{l}\text { prototipe yang akan } \\
\text { diujicobakan secara } \\
\text { bertahap dan direvisi } \\
\text { berdasarkan tahap } \\
\text { evaluasi formatif }\end{array}$ \\
\hline $\begin{array}{l}\text { Tahap } \\
\text { Penilaian }\end{array}$ & Praktikalitas & $\begin{array}{l}\text { Menilai apakah } \\
\text { pengguna dapat } \\
\text { menggunakan produk } \\
\text { dengan praktis } \\
\text { (praktikalitas) }\end{array}$ \\
\hline
\end{tabular}

\subsection{Preliminary research (penelitian pendahuluan)}

Penelitian pendahuluan dilakukan analisis struktur isi kurikulum, analisis konsep dan analisis karakter guru. Pada analisis struktur isi kurikulum ini dilakukan analisis pada materi mikrotik berdasarkan acuan TKJ kurikulum yang berlaku pada sekolah saat ini. Analisis ini dimaksudkan untuk mengetahui tujuan dari mata pelajaran untuk dapat mengembangkan modul dengan tepat. Analisis Konsep dilakukan dengan menganalisis materi yang ada lalu meneliti dan menelaahnya kemudian memilih satu konsep yang tepat yang akan dikembangkan dalam penelitian ini. Analisis guru dilakukan agar mengetahui karakter dari guru agar pengembangan e-modul sesuai dengan karakter pemakai dan dapat berfungsi lebih efektif dan efisien digunakan.

\subsection{Prototyping stage (pengembangan prototype)}

Hasil rancangan e-modul pelatihan mikrotik kemudian dievaluasi dan disempurnakan secara bertahap berdasarkan tahap evaluasi formatif. Tahap-tahap evaluasi formatif terdiri dari evaluasi sendiri (self evaluation), tinjauan para ahli (experts review), evaluasi perorangan (one-to-one evaluation), evaluasi

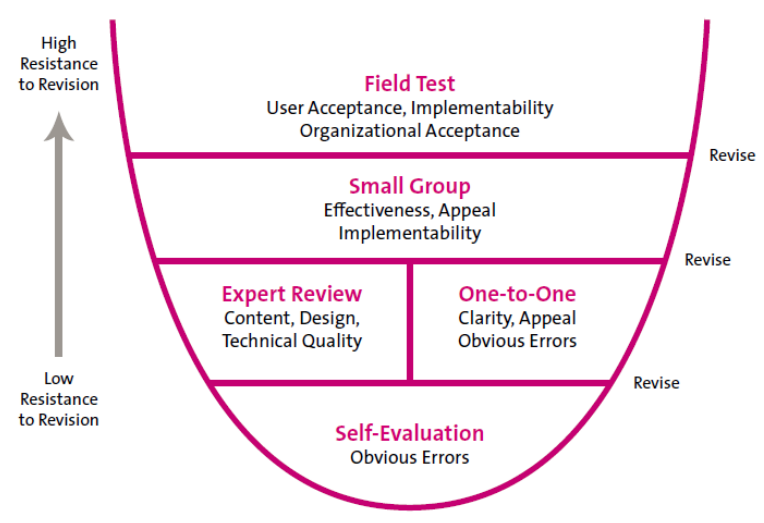

Gambar 1. Langkah pada prototype stage (ploomp) [9]

\subsection{Assesment phase (fase penilaian)}

Tahap assesment stage digunakan untuk mengetahui kepraktisan dari produk yang akan dikembangkan.

Praktikalitas adalah tingkat kepraktisan dan keterlaksanaan prototype produk oleh instruktur dan peserta diklat, yaitu melaksanakan percobaan pelatihan menggunakan e-modul pelatihan yang telah direvisi sesuai dengan hasil pada prototype I dan prototype II.

Pelaksanaan uji coba lapangan e-modul pelatihan mikrotik guru teknik informatika bidang kompetensi teknik komputer jaringan dilaksanakan kepada 30 Guru Teknik Komputer Jaringan

Populasi penelitian pada SMK Negeri yang memiliki jurusan Teknik komputer jaringan, yaitu SMKN 2 Padang memilki 3 orang guru TKJ, SMKN 3 Padang memilki 7 orang guru TKJ, SMKN 5 Padang memilki 4 orang guru TKJ, SMKN 6 Padang memilki 8 orang guru TKJ, dan SMKN 8 Padang memilki 10 orang guru

Tabel 3. Sampel Penelitian Guru TKJ di Kota Padang

\begin{tabular}{lcc}
\hline No & Nama Sekolah & Jumlah Guru TKJ \\
\hline 1 & SMK Negeri 2 Padang & 3 Orang \\
2 & SMK Negeri 3 Padang & 7 Orang \\
3 & SMK Negeri 5 Padang & 4 Orang \\
4 & SMK Negeri 6 Padang & 8 Orang \\
5 & SMK Negeri 8 Padang & 10 Orang \\
Total & & 32 Orang \\
\hline
\end{tabular}

Analisis validitas menggunakan skala likert berdasarkan angket validitas dengan langkah-langkah: Skor masing-masing menggunakan skala likert 1-5, menjumlahkan skor tiap validator untuk seluruh validator, pemberian nilai validitas dengan cara statistik aiken'n $\mathrm{V}$

$$
V=\sum s /[n(c-1)]
$$

Dengan $\mathrm{s}=\mathrm{r}-\mathrm{I}_{0} ; \mathrm{I}_{0}=$ angka penilaian validitas yang terendah; $\mathrm{c}=$ angka penilaian validitas yang tertinggi; $r$ $=$ angka yang diberikan oleh seorang penilai 
Hasil dari perhitungan Aiken'V berkisar antara 0 sampai 1,00 dan angka 0,3 dapat diinterpretasikan memiliki koefisien cukup tinggi maka nilai $\mathrm{V} 0.3$ dan di atasnya dinyatakan dalam kategori valid [10].

Tabel 4. Kategori Kriteria Respon

\begin{tabular}{llc}
\hline No & \multicolumn{1}{c}{ Tingkat Pencapaian } & kategori \\
\hline 1 & $0,3-1,00$ & Valid \\
2 & $<0,3$ & Tidak Valid \\
\hline
\end{tabular}

Analisis kepraktisan menggunakan skala likert berdasarkan angket praktikalitas, dengan langkahlangkah seperti Penskoran masing-masing dengan skala likert 1-5, menentukan skor rata-rata yang didapatkan dengan cara menjumlahkan nilai yang didapat dari banyak indicator, pemberian nilai praktis dengan rumus

$$
N A=\frac{S}{S M} \times 100 \%
$$

Dengan NA = nilai akhir; $\mathrm{S}=$ skor yang di dapatkan; $\mathrm{SM}=$ skor maksimum[11].

Tabel 5. Kategori praktikalitas E-Modul [12].

\begin{tabular}{llc}
\hline No & Tingkat Pencapaian & kategori \\
\hline 1 & $81-100$ & Sangat Praktis \\
2 & $61-80$ & Praktis \\
3 & $41-60$ & Cukup Praktis \\
4 & $21-40$ & Kurang Praktis \\
5 & $0-20$ & Tidak Praktis \\
\hline
\end{tabular}

\section{Hasil dan Pembahasan}

Hasil penelitian di peroleh melalui beberapa langkah penelitian, yaitu preliminary research (penelitian pendahuluan), prototyping stage (pengembangan prototype), assesment phase (fase penilaian).

\subsection{Preliminary research (penelitian pendahuluan)}

Analisis kurikulum mengacu pada kurikulum yang di kuasai oleh guru teknik komputer jaringan, dengan materi yang berkaitan dengan mikrotik, yaitu Konfigurasi dasar, DHCP, Bridge, Routing, Wireles,
Firewall, QoS, Tunnels. Analisis materi dilakukan dengan mereview buku-buku yang membahas tentang mikrotik. Kemudian peneliti menuangkan poin-poin materi ke dalam E-Modul Pelatihan Mikrotik. Setelah melakukan berbagai analisis maka konsep yang diadopsi untuk dikemas dalam E-Modul pelatihan mikrotik adalah materi mikrotik tingkat dasar. Pada analisis peserta diklat melaksanakan pembelajaran secara individu dengan menggunakan e-modul pelatihan, sehingga peserta diklat bisa melihat dan mempelajari sendiri bagaimana e-modul pelatihan bisa meningkatkan pemahaman guru tentang mikrotik

\subsection{Prototyping stage (pengembangan prototype)}

Pada langkah pengembangan prototype ini dilakukan untuk menguji modul yang dikembangkan:

Pada Prototype I ini modul yang telah dikembangkan dilihat dan direvisi sendiri oleh peneliti.

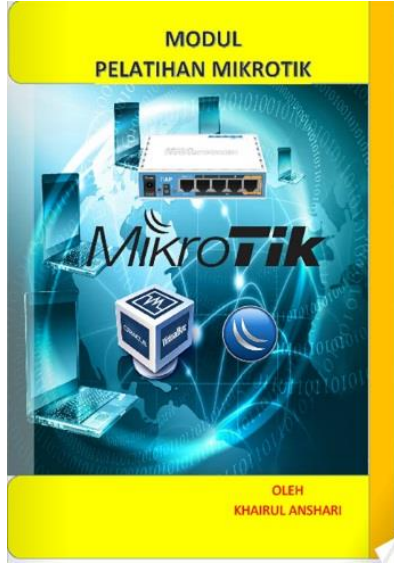

Gambar 2. Tampilan Cover E-Modul Pelatihan Mikrotik

Cover teresebut merupakan halaman luar dari modul yang dibuat dengan menggunakan software photoshop. Dengan menampilkan router board, virtualbox, winbox dan simbol dari mikrotik yang merupakan bagian dari mikrotik.

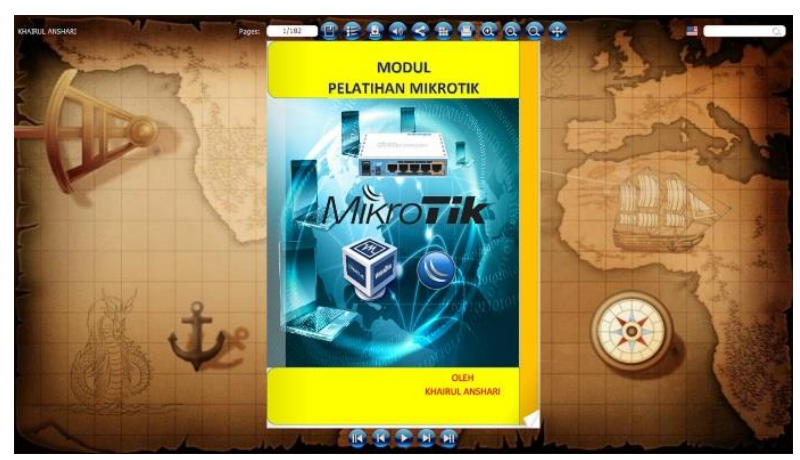

Gambar 5. Tampilan Menu Utama E-Modul Pelatihan Mikrotik

Halaman utama menampilkan cover modul yang dimasukkan kedalam aplikasi flipbooks, dengan tampilan tambahan background, beberapa icon navigasi sebagai panduan penggunaan modul
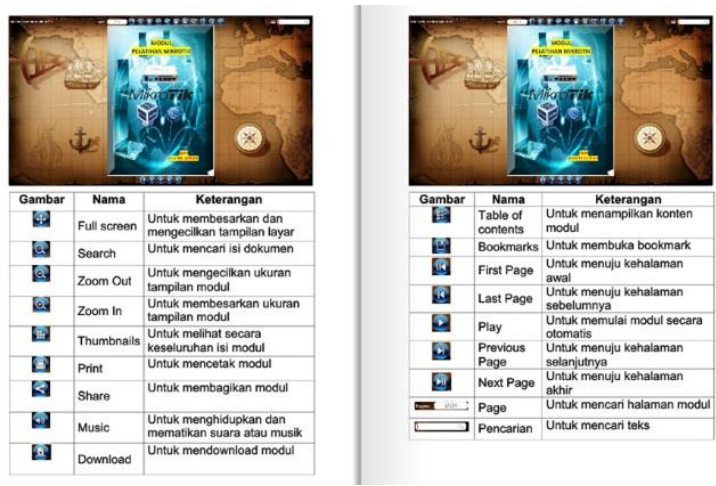

Gambar 3. Tampilan Halaman Penggunaan Modul

Panduan penggunaan modul menampilkan fungsifungsi dari icon navigasi penggunaan modul, mulai dari pengaturan ukuran layar, menjalankan aplikasi, mencari halaman atau teks yang diinginkan, pengaturan suara dan download. 


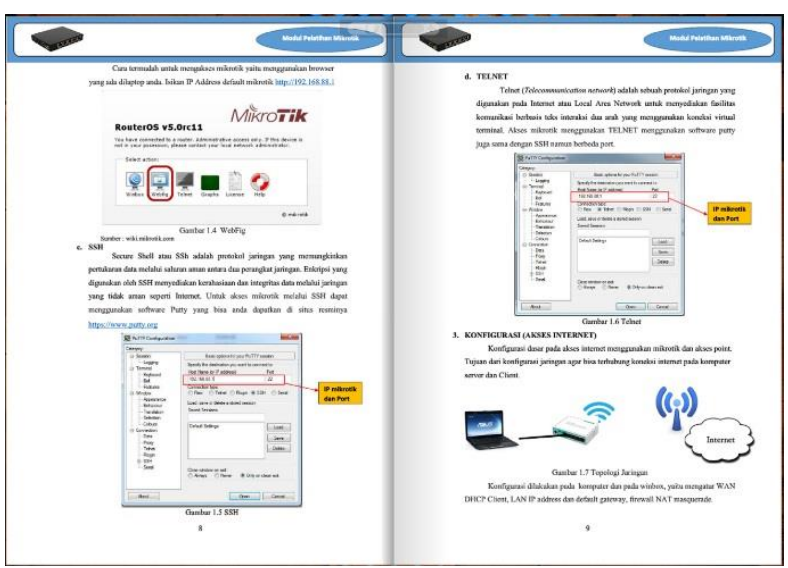

Gambar 4. Tampilan Halaman Studi

Pada halaman studi menampilkan isi dari materi modul mikrotik, dimulai dari pendahuluan hingga materi dari kegiatan belajar awal hingga akhir.

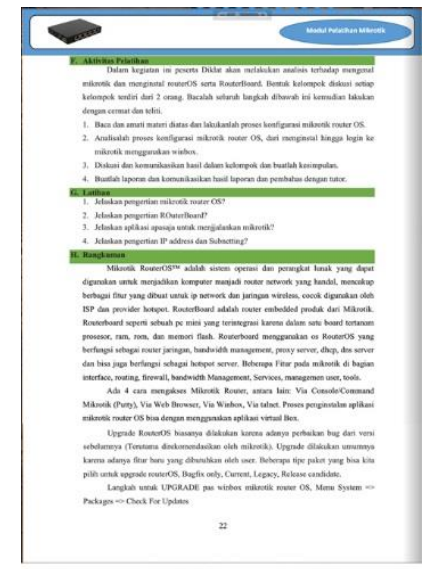

Gambar 5.Tampilan Halaman Latihan

Pada halaman latihan menampilkan beberapa soal yang dibahas untuk mengetahuii seberapa jauh pemahaman peserta diklat pada materi pada setiap kegitan belajar.

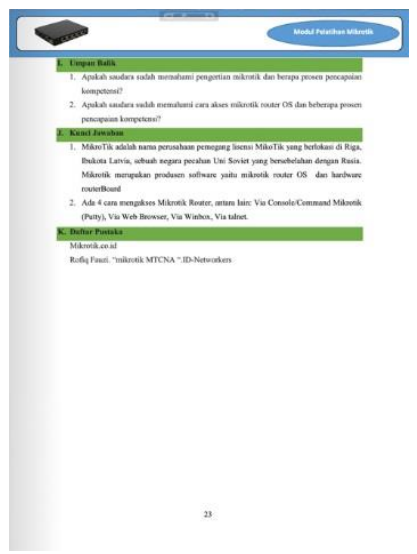

Gambar 9. Tampilan Halaman Kunci Jawaban

Halaman ini menampilkan jawaban untuk soal diskusi yang terdapat didalam modul, tujuan dari kunci jawaban untuk mengetahui jawaban dari pembahasan diskusi

Pada Prototype II ini dilakukan evaluasi perorangan. Evaluasi perorangan ini yaitu dengan menemui 6 orang pakar untuk dimintai masukan perbaikan pada modul yang dikembangkan

Hasil data penilaian validasi e-modul oleh para ahli media dapat dilihat pada Tabel 6 .

Tabel 6. Hasil Validasi Terhadap E-Modul Pelatihan

\begin{tabular}{llllll}
\hline No & $\begin{array}{l}\text { Aspek } \\
\text { Validasi }\end{array}$ & V1 & V2 & V3 & Kategori \\
\hline 1 & $\begin{array}{l}\text { Syarat } \\
\text { Didaktik }\end{array}$ & & & & \\
2 & $\begin{array}{l}\text { Syarat } \\
\text { Konstruksi }\end{array}$ & 0,92 & 0,87 & 0,89 & Valid \\
& $\begin{array}{l}\text { Syarat } \\
\text { Teknis }\end{array}$ & & & & \\
& & & & \\
\hline
\end{tabular}

Hasil analisis terhadap lembar validasi modul dengan 3 aspek yaitu aspek didaktik, aspek konstruksi dan aspek teknis oleh 3 orang validator ahli modul memperoleh hasil dari validator 1 dengan rata-rata 0,92 dengan kategori valid, dari validator 2 dengan rata-rata 0,87 dengan kategori valid, dan dari validator 3 dengan ratarata 0,89 dengan kategori valid, berdasarkan hasil 3 orang validator diperoleh kesimpulan bahwa modul dikategorikan valid. Hasil dari validasi materi dapat dilihat pada Tabel 7 .

Tabel 7. Data Validasi Materi Terhadap E-modul pelatihan

\begin{tabular}{llllll}
\hline No & \multicolumn{1}{c}{$\begin{array}{c}\text { Aspek } \\
\text { Validasi }\end{array}$} & V1 & V2 & V3 & Kategori \\
\hline 1 & Kualitas Isi & & & & \\
2 & $\begin{array}{l}\text { Kualitas } \\
\text { Pembelajaran }\end{array}$ & & & & \\
3 & $\begin{array}{l}\text { Kualitas } \\
\text { Interaksi }\end{array}$ & 0,84 & 0,83 & 0,82 & Valid \\
4 & Kualitas & & & & \\
& Tampilan & & & & \\
\hline
\end{tabular}

Berdasarkan validasi modul maka dapat disimpulkan bahwa modul dikatakan valid. Pada validasi materi dengan 4 aspek di peroleh kualitas isi, kualitas pembelajaran, kualitas interaksi, dan kualitas tampilan, berdasarkan 3 orang ahli materi diperoleh dari validator 1 dengan rata-rata 0,84 dengan kategori valid, validator 2 dengan rata-rata 0,83 dengan kategori valid, dan validator 3 dengan rata-rata 0,82 dengan kategori valid berdasarkan hasil validasi materi diperoleh kesimpulan bahwa materi modul dikategorikan valid.

\subsection{Assesment Stage (Fase Penilaian)}

Tahap Assesment Stage digunakan untuk mengetahui kepraktisan modul yang sudah dikembangkan. Hasil angket praktikalitas untuk respon instruktur angket praktikalitas yang diberikan kepada peserta diklat.

Jurnal RESTI (Rekayasa Sistem dan Teknologi Informasi) Vol . 3 No. 3 (2019) 538 - 543 
Tabel 8. Data Praktikalitas

\begin{tabular}{llcr}
\hline No & Aspek & Instruktur & Peserta Diklat \\
\hline 1 & Kemudahan & $86,67 \%$ & $84,75 \%$ \\
2 & Waktu & $86 \%$ & $77,33 \%$ \\
3 & Daya Guna & $85 \%$ & $78,86 \%$ \\
Rata-rata total & $85,89 \%$ & $80,31 \%$ \\
Kategori & Sangat Praktis & Sangat Praktis \\
\hline
\end{tabular}

Hasil penelitian praktikalitas e-modul pelatihan berdasarkan respons peserta diklat terhadap waktu, dan penggunaan e-modul termasuk kategori praktis. praktis berdasarkan hasil analisis terhadap angket respon instruktur pada 3 aspek, dari aspek kemudahan diperoleh hasil $86,67 \%$ dengan kategori praktis, pada aspek efektifitas waktu diperoleh hasil $86 \%$ dengan kategori praktis, pada aspek pemanfaatan di peroleh hasil $85 \%$ dengan kategori praktis, berdasarkan hasil perhitungan diperoleh rata-rata nilai $85,89 \%$ maka dapat disimpulkan bahwa modul pelatihan menurut instruktur dikatakan praktis.

Respon Peserta diklat dari aspek kemudahan diperoleh hasil $84,75 \%$ dengan kategori praktis, pada aspek efektifitas waktu diperoleh hasil $77,33 \%$ dengan kategori praktis, pada aspek pemanfaatan di peroleh hasil 78,86\% dengan kategori praktis, berdasarkan hasil perhitungan diperoleh rata-rata nilai $80,31 \%$ maka dapat disimpulkan bahwa modul pelatihan dikatakan praktis.

Hasil akhir dari penelitian ini adalah sebuah e-modul pelatihan mikrotik yang digunakan oleh guru untuk meningkatkan kemampuan kompetensi guru pada bidang teknik komputer jaringan tentang mikrotik. Emodul meningkatkan motivasi dan hasil belajar [13].

\section{Kesimpulan}

Berdasarkan proses dan hasil penelitian e-modul pelatihan mikrotik guru teknik informatika bidang teknik komputer jaringan dengan aplikasi flipbooks dan model pengembangan Plomp dan Nieveen yang terdiri dari tahap penelitian pendahuluan, tahap pengembangan dan tahap penilaian diperoleh kesimpulan bahwa

Telah dikembangakan E-modul pelatihan mikrotik guru teknik informatika bidang teknik komputer jaringan yang valid oleh ahli materi dan ahli modul, sehingga modul layak dan bisa untuk digunakan oleh peserta diklat. E-modul pelatihan mikrotik juga dinilai praktis oleh instruktur dan peserta diklat dengan rata-rata nilai $85,89 \%$ berdasarkan angket praktikalitas, sehingga emodul mudah digunakan untuk meningkatkan pemahaman dan motivasi pada pelatihan mikrotik.

Berdasarkan kesimpulan dan temuan maka implikasi pada penelitian ini adalah e-modul pelatihan mikrotik dapat dijadikan sumber belajar mikrotik pada bidang dasar dan memberikan kemudahan dalam pelatihan sehingga berpengaruh pada efektifitas proses pelatihan dan meningkatkan hasil pelatihan peserta diklat. Guru perlu menggunakan modul dimanapun dan kapanpun dengan media laptop untuk menjalankan modul. Guru yang belum bisa mikrotik mendapatkan tambahan pengetahuan tentang penggunaan mikrotik, serta cara mengatur instalasi dan pengamanan mikrotik. Guru dapat ide untuk mengembangkan alat bantu belajar dengan menggunakan aplikasi flipbooks untuk kegiatan belajar tentang teknik komputer dan jaringan

Berdasarkan hasil penelitian maka peneliti menyarankan agar e-modul pelatihan mikrotik yang dikembangkan ini cocok menjadi rujukan untuk digunakan oleh peserta diklat di sekolah masingmasing. Diharapkan e-modul pelatihan ini dapat di uji coba lanjutan pada beberapa sekolah lain untuk melihat praktikalitas serta menilai efektivitas dari modul. Bagi peneliti selanjutnya disarankan untuk memberikan inovasi dalam mengembangkan e-modul pelatihan mikrotik

\section{Daftar Rujukan}

[1] Dessler, G.. 2013. Human Resource Management. (fifteenth Edition). Florida International University : Pearson

[2] Ivanceich M. John. 2013. Human Resource Management. Twelfth Edition. :McGrawHill

[3] Noe, R.A., 2012. Human Resource Mangement : Gaining A Competitive Advantage.McGrawHill

[4] Direktorat Pembina Sekolah Menengah Kejuruan. 2008. Petunjuk teknis pelaksanaan kurikulum tingkat satuan pendidikan. Jakarta. direktorat pembina sekolah mengengah kejuruan

[5] E Mulyasa. 2015. Kurikulum Berbasis Kompetensi, Konsep Karakteristik Implementasi Dan Inovasi. Bandung : PT. Remaja Rosdakarya

[6] Roza L Herdini, Ika, S.S., Teja P.P., 2018. Interactive EModule Development through Chemistry Magazine on Kvisoft Flipbook Maker Application for Chemistry Learning in Second Semester at Second GradeSenior High School Jurnal Of Science Learning. 2 (1), 21-25 DOI: https://doi.org/10.17509/jsl.v2i1.12933

[7] Sunismi dan Fathani 2016 Uji Validasi E-Module Matakuliah Kalkulus I untuk Mengoptimalkan Student Centered Learning dan Individual Learning Mahasiswa S-1. Jurnal Review Pembelajaran Matematika $1 \quad$ (2), $\quad$ 174-191. https://doi.org/10.15642/jrpm.2016.1.2.174-191

[8] Sugiyono. 2013. Metode Penelitian Kuantitatif, Kualitatif dan $R \& D$. Bandung. Alfabeta

[9] Ploomp Tjeerd \& Nieveen Nienke. 2013. An Introduction to Educational Design Reseach. Neteherland. Enschede

[10] Azwar. Saifuddin. 2013. Metode Penelitian . Yogyakarta: Pustaka Pelajar

[11] Suharsimi Arikunto. 2010. Dasar-Dasar Evaluasi Pendidikan. Jakarta. Rineka Cipta

[12] Riduwan. 2010. Belajar Mudah Penelitian Untuk GuruKaryawan Dan Peneliti Pemula. Bandung. CV. Alfabeta

[13] Imron Hamzah, Sriyani Mentari, 2016. Development of Accounting E-Module to Support the Scientific Approach of Students Grade X Vocational High School. Journal of Accounting And Business Education, 2 (1), 78-88 DOI: http://dx.doi.org/10.26675/jabe.v1i1.9751 